\title{
Effect of maturation on hemodynamic and autonomic control recovery following maximal running exercise in highly trained young soccer players
}

\section{Martin Buchheit* , Hani Al Haddad, Alberto Mendez-Villanueva, Marc J. Quod and Pitre C. Bourdon}

Physiology Unit, Sport Science Department, ASPIRE Academy for Sports Excellence, Doha, Oatar

\section{Edited by:}

J. A. Taylor, Harvard University, USA

Reviewed by:

David Poole, Kansas State University, USA

Can Ozan Tan, Harvard Medical School, USA

\section{*Correspondence:}

Martin Buchheit, Physiology Unit, Sport Science Department, ASPIRE, Academy for Sports Excellence, P.O. Box 22287, Doha, Qatar. e-mail: martin.buchheit@aspire.qa; mb@martin-buchheit.net

The purpose of this study was to examine the effect of maturation on post-exercise hemodynamic and autonomic responses. Fifty-five highly trained young male soccer players (12-18 years) classified as pre-, circum-, or post-peak height velocity (PHV) performed a graded running test to exhaustion on a treadmill. Before (Pre) and after (5th-10th min, Post) exercise, heart rate (HR), stroke volume (SV), cardiac output (CO), arterial pressure (AP), and total peripheral resistance (TPR) were monitored. Parasympathetic (high frequency $\left[\mathrm{HF}_{\mathrm{RR}}\right]$ of HR variability (HRV) and baroreflex sensitivity [Ln BRS]) and sympathetic activity (low frequency [ $\left[\mathrm{F}_{\mathrm{SAP}}\right.$ ] of systolic AP variability) were estimated. Post-exercise blood lactate $[\mathrm{La}]_{b}$, the HR recovery (HRR) time constant, and parasympathetic reactivation (time-varying HRV analysis) were assessed. In all three groups, exercise resulted in increased $\mathrm{HR}, \mathrm{CO}, \mathrm{AP}$, and $\mathrm{LF}_{\mathrm{SAP}}(P<0.001)$, decreased SV, HF RR, and Ln BRS (all $\left.P<0.001\right)$, and no change in TPR $(P=0.98)$. There was no "maturation $\times$ time" interaction for any of the hemodynamic or autonomic variables (all $P>0.22$ ). After exercise, pre-PHV players displayed lower $\mathrm{SV}, \mathrm{CO}$, and $[\mathrm{La}]_{b}$, faster HRR and greater parasympathetic reactivation compared with circum- and post-PHV players. Multiple regression analysis showed that lean muscle mass, $[\mathrm{La}]_{b}$, and Pre parasympathetic activity were the strongest predictors of $\operatorname{HRR}\left(r^{2}=0.62, P<0.001\right)$. While pre-PHV players displayed a faster HRR and greater post-exercise parasympathetic reactivation, maturation had little influence on the hemodynamic and autonomic responses following maximal running exercise. HRR relates to lean muscle mass, blood acidosis, and intrinsic parasympathetic function, with less evident impact of post-exercise autonomic function.

Keywords: heart rate variability, blood pressure variability, parasympathetic reactivation, age, impedance cardiography

\section{INTRODUCTION}

The assessment of pre- and post-exercise autonomic nervous system (ANS) activity via resting heart rate (HR) variability (HRV) and post-exercise HR recovery (HRR) in athletes has been of growing interest in the recent years (Iellamo et al., 2002; Iwasaki et al., 2003; Garet et al., 2004; Gratze et al., 2005, 2008; Bosquet et al., 2007; Buchheit et al., 2008, 2010a; Manzi et al., 2009) because of their ability to predict (changes in) physical performance. Measures of HRR and pre- and post-exercise HRV in the field have been shown to be reliable (Buchheit et al., 2010c; Al Haddad et al., 2011) and more importantly, very convenient for athletes as they are non-invasive, cheap, and can be easily implemented into their training schedule (Buchheit et al., 2008, 2010a, 2011). However, the majority of these aforementioned studies have been conducted on adults, and the capability of these measures to predict physical performance in children and adolescents has not been widely investigated (Buchheit et al., 2008, 2011). Additionally, the value of using HRR and HRV measures to estimate hemodynamic and autonomic control recovery responses following exercise in children and adolescents is still unknown.
The recovery of hemodynamic [cardiac output (CO), HR, arterial pressure (AP)] and respiratory (ventilation, oxygen uptake, and carbon dioxide production) variables have been shown to be faster in children compared with adolescents and adults (Ratel et al., 2006). In adults, post-exercise hemodynamic recovery is controlled by complex interactions between neural and humoral factors (Rowell and O'Leary, 1990). While parasympathetic reactivation (Imai et al., 1994) and central sympathetic nerve activity withdrawal (Savin et al., 1982) have been suggested to be the strongest determinants of post-exercise hemodynamic recovery, contraction-induced increases in skeletal muscle metabolites (e.g., plasma epinephrine, lactate, $\mathrm{H}^{+}$, inorganic phosphate; Vissing, 2000; Kaufman and Hayes, 2002) play an important role via both the arterial chemoreflex (Rowell and O'Leary, 1990) and muscle metaboreflex (Kaufman and Hayes, 2002) control of HR. However, whether the determinants of post-exercise hemodynamic and autonomic control responses are similar in young children and adolescents is still unclear, especially because of their maturational differences in ANS activity (Finley and Nugent, 1995; Pikkujamsa et al., 1999), arterial stiffness (Lenard et al., 2004), arterial pressure regulation, body size, muscle characteristics, and energy system 
metabolisms (i.e., the younger have a greater reliance on oxidative metabolism associated with an immature anaerobic function; Ratel et al., 2006).

Until now, the faster HRR kinetics observed in children have been shown to be related to their high-functioning parasympathetic system measured either before (Ohuchi et al., 2000) or after exercise (Goulopoulou et al., 2006), and also to their lower absolute work rate and less developed anaerobic function (Buchheit et al., 2010b). Nevertheless, in all these previous studies, measures were limited to HR (i.e., HRR and HRV measures), which does not allow a systemic understanding of the mechanisms governing postexercise cardiovascular responses in young individuals. Although HRV measures can (only) provide a qualitative maker of cardiac parasympathetic regulation (Task Force, 1996; Malliani et al., 2006), additional information regarding sympathetic vasomotor tone can be gained by evaluating the low frequency power of AP variability (Parati et al., 1995). Additionally, the importance of the aforementioned factors in determining post-exercise HRR in young individuals is still unknown. Concurrent measures of postexercise stroke volume (SV), CO, AP, total peripheral resistance (TPR), as well as spontaneous baroreflex sensitivity (BRS), and arterial pressure variability in adolescents over a wide range of maturation levels might therefore enable a more comprehensive understanding of the determinants of post-exercise HRR in young individuals.

The main purposes of the present study were therefore to (1) examine maturational differences in hemodynamic (HR, SV, CO, AP, TPR) and autonomic control (HRV, AP variability, and BRS) recovery following maximal running exercise, (2) compare the respective importance of selected autonomic control and nonautonomic predictors of post-exercise HRR, and (3) examine the relationships between HRR, ANS control, and selected markers of (aerobic-related) physical performance. We first expected the less mature players to present a lower exercise pressor response (e.g., lower elevation in AP and blood lactate accumulation) associated with a faster recovery of all hemodynamic and markers of autonomic control. It was also hypothesized that blood acidosis, lean body mass, pre- and post-exercise ANS activity (both parasympathetic modulation and sympathetic vasomotor tone) would be the strongest predictors of post-exercise HRR. However, given the possible maturational differences in (resting) ANS control and the determinants of (aerobic-related) physical performance, whether the associations between HRR, ANS activity, and physical performance would be affected by maturation status was difficult to predict.

\section{MATERIALS AND METHODS PARTICIPANTS}

Fifty-five highly trained young male soccer players across six different age groups ranging from Under 13 to Under 18 were classified into three distinct maturity-based groups [pre-, circum-, and postpeak height velocity (PHV); Table 1]. Because of the uncertainty in their birth dates, we did not include players with an African background. All the players participated on average in $\sim 14 \mathrm{~h}$ of combined soccer-specific training and competitive play per week ( six to eight soccer training sessions, one strength training session, one to two conditioning sessions, one domestic game per week and two international level club games every 3 weeks). All players had a history of at least 3 years of soccer-specific training. Players were; all familiar with exercise testing, not taking prescribed medications and presented with normal blood pressure levels and electrocardiographic patterns. None of the players was underperforming and complaining about any type of fatigue at the time of the experimentation. All players and their parents gave voluntary written consent to participate in the experiment. This study was approved by the local research ethics committee and conformed to the recommendations of the Declaration of Helsinki.

\section{ANTHROPOMETRIC MEASURES AND MATURITY STATUS DETERMINATION}

All anthropometric measures were taken in the morning by the same experienced anthropometrist. Dimensions included stretch stature, body mass, sitting height, and sum of seven skinfolds (triceps, subscapular, biceps, supraspinale, abdominal, front thigh, and medial calf). Stretch stature was measured using a wallmounted stadiometer $( \pm 0.1 \mathrm{~cm}$, Holtain Ltd., Crosswell, UK), sitting height with a stadiometer mounted on a purpose-built table $( \pm 0.1 \mathrm{~cm}$, Holtain Ltd., Crosswell, UK), body mass with a digital balance $( \pm 0.1 \mathrm{~kg}$, ADE Electronic Column Scales, Hamburg, Germany), and skinfold thicknesses with a Harpenden skinfold caliper ( $\pm 0.1 \mathrm{~mm}$, Baty International, Burgess Hill, UK). Landmarks for each skinfold measurement was in accordance with previously described procedures (Marfell-Jones et al., 2006) with all skinfold measurements taken on the right side of the body. Body fat percentage was calculated using the equations of Slaughter et al. (1988) as these equations have been suggested to be the most accurate for estimating body fat percentage from skinfold thickness in an adolescent population (Rodriguez et al., 2005). Lean body mass $(\mathrm{kg})$ was derived by subtracting body fat mass from total body mass. The age at PHV was used as a relative indicator of somatic maturity representing the time of maximum growth in

Table 1 | Anthropometric variables of highly trained young soccer players grouped according to maturity status.

\begin{tabular}{|c|c|c|c|c|c|c|}
\hline & Age (years) & Age to/from PHV (years) & Height (cm) & Body mass (kg) & Lean body mass (kg) & Total skinfolds (mm) \\
\hline Circum-PHV & $14.3 \pm 0.7^{*}$ & $0.0 \pm 0.4^{*}$ & $162.7 \pm 5.5^{*}$ & $47.7 \pm 5.4^{*}$ & $41.5 \pm 4.6^{*}$ & $44.1 \pm 12.1$ \\
\hline
\end{tabular}

Values are means $\pm S D$. PHV, peak height velocity. pre-PHV, circum-PHV, and post-PHV, peak height velocity group; total skinfolds: sum of seven skinfolds (triceps, biceps, subscapular, front thigh, medial calf, abdominal, and supraspinale) *, significantly different from pre-PHV $(P<0.05)$. ${ }^{+}$, Significantly different from circum-PHV $(P<0.05)$. 
stature during adolescence as described by Mirwald et al. (2002). Age at PHV is the most commonly used indicator of maturity in longitudinal studies of adolescence (Malina et al., 2004). Ethnicity of the players was Arab (Middle Eastern; considered as "white" on the Census forms, same as the Canadian adolescents who served to determine the initial regressions to estimate age at PHV; Mirwald et al., 2002). The effect of ethnicity on the validity of biological maturity estimates using the procedures described above is presently unknown; the equation was therefore assumed to be valid for the present sample (Buchheit et al., 2010c,d,e, 2011; MendezVillanueva et al., 2011). Though there is no evidence to suggest that ethnicity per se may affect the relation between anthropomorphic measurements and estimated PHV, we acknowledge that the latter can be influenced by other factors such as dietary and nutritional habits and genetic make-up. Data derived from a sample of 90 young soccer players [age range: $12.1-17.3$ years] in our academy showed that age from/to PHV is well correlated $(r=0.69,90 \% \mathrm{CI}$; 0.59-0.77) with skeletal age (SA; estimated from a hand and wrist radiograph; Gilsanz-Ratib's bone age atlas; Gilsanz and Ratib, 2005). However, in comparison to SA, which is basically a method to estimate the absolute level of maturity which a child has attained at a given point in time, the age from/to PHV is a common landmark to reflect the occurrence of important physiological changes within individuals (both quantitatively [body size] and qualitatively [hormonal, metabolic, and possibly autonomic functions as examined in the present study]; Malina et al., 2004). Additionally, the assessment of SA also suffers from important methodological limitations, which further encouraged us to retain only the PHV measures as an indicator of somatic maturity: (1) because of the different determination methods, the possibility to use different bones (i.e., more than 20 bones can be used) and important interindividual differences in the rate of bone growth, using SA as the gold standard method is not that straightforward (Beunen, 1989; Malina et al., 2004); and (2) SA determination requires a comparison against a reference value. For all methods currently available (e.g., Greulich-Pyle, Tanner-Whitehouse, Gilsanz-Ratib, or Fels), the reference values were obtained on "white" American or English children and adolescents. Thus, current available methods for SA determination also rely on a metric validated only on a "white" population. As such, the use of SA in the present study would have the same limitation as age from/to PHV regarding the ethnicity of the players examined in the present study. Therefore, while SA data were available for a subsample of the players included in the present study, we decided, based on the aforementioned facts, neither to directly use SA, nor to adjust the statistical analyses for SA. Biological age of relative maturity (y) was therefore calculated by subtracting the actual chronological age at the time of measurement from the calculated peak-velocity age. Thus, a maturity age of -1.0 year indicates that the player was measured 1 year before reaching PHV; a maturity age of 0 year indicates that the player was measured at the time of their PHV; and a maturity age of +1.0 year indicates that the player was measured 1 year after their PHV. Because all estimations are still subject to errors of measurement, and since predictions are never perfect, some participants may have been assigned to the wrong maturational group. An initial data analysis also showed that differences in hemodynamic and autonomic control variables were more evident when players were grouped based on the estimated maturation status than on age. That was probably related to the fact that the standard deviation for the age to/from PHV in each age group (e.g., under 14, 16, and 18 ) was $60 \%$ higher than in each maturity group (observing different maturational status in adolescents of similar chronological age is common in the pediatric literature; Mirwald et al., 2002; Malina et al., 2004). For all the aforementioned reasons, and while acknowledging these possible limitations, we chose to classify the players based on their estimates of maturation, and not their chronological age. Twenty players were finally classified as pre-PHV ( $<-1$ year from PHV), 19 as circum-PHV ( -1 to 1 year from PHV), and 15 as post-PHV ( $>1.5$ years from PHV). The limits of these groups were adjusted to have comparable sample sizes.

\section{EXPERIMENTAL OVERVIEW}

All players were tested in an environmentally controlled exercise laboratory $\left(22-23^{\circ} \mathrm{C}\right)$ within 2 months of the start of the competitive season. Players were first monitored for $10 \mathrm{~min}$ at rest (seated, without any movement, or talking) to measure resting hemodynamic and autonomic variables (using a Task Force Monitor, CNSystems, Graz, Austria, see below). Players then performed an incremental running test to exhaustion on a motorized treadmill (Woodway PPS Med, Woodway, Waukesha, WI, USA). All players consumed their last meal at least $2 \mathrm{~h}$ before the test and refrained from intensive exercise in the $24 \mathrm{~h}$ period preceding testing. The incremental running test began with an initial speed of $8 \mathrm{~km} \mathrm{~h}^{-1}$ and increased $1 \mathrm{~km} \mathrm{~h}^{-1}$ every minute until the players stopped due to volitional exhaustion. During the running test, only respiratory (Oxycon Pro, Jaeger, Hoechberg, Germany) and beatby-beat HR responses (S810 HR monitor, Polar Electro, Kempele, Finland) were recorded (i.e., the Task Force Monitor was removed just before exercise). Players were seated within $5 \mathrm{~s}$ of the end of the running test and were required to remain quietly seated for another $10 \mathrm{~min}$. The Task Force Monitor was refitted to the players within 2 min of completing the run and after a further 1- to 2-min calibration period, all hemodynamic and autonomic variables were continuously recorded for the remainder of the recovery period (i.e., from 4 th to 10 th $\mathrm{min}$ ).

\section{MEASUREMENTS OF HEMODYNAMIC AND AUTONOMIC VARIABLES}

The Task Force Monitor was used to continuously monitor beatby-beat measures of: HR (beats $\mathrm{min}^{-1}$ ) using ECG, beat-by-beat SV ( $\mathrm{ml}$ ) by an improved method of impedance cardiography (Fortin et al., 2006) and beat-by-beat blood pressure (systolic, diastolic, and mean arterial pressure, SAP, DAP, and MAP, respectively) by the vascular unloading technique (Parati et al., 2003), which was corrected automatically to the oscillometric blood pressure measured on the contralateral arm. These calculations were all done using the Task Force Monitor software. TPRs were calculated according to Ohm's law $[\mathrm{TPR}=((\mathrm{MAP}-\mathrm{CVP}) / \mathrm{CO}) \times 80$, where CVP stands for central venous pressure which by default was set at $3 \mathrm{mmHg}$ ]. Using power spectral analysis and applying an autoregressive methodology, the Task Force Monitor automatically measured: (1) the $0.04-$ to $0.15-\mathrm{Hz}$ (low frequency, $\mathrm{LF}_{\mathrm{RR}}$ ) and $>0.15-$ to $0.40-\mathrm{Hz}$ bands (high frequency, $\mathrm{HF}_{\mathrm{RR}}$ ) for assessing HR interval variability (where RR is R-wave to R-wave) and (2) 
the $0.04-$ to $0.15-\mathrm{Hz}$ band for SAP and DAP variability. All APderived indices were computed in absolute values (LFSAP and $\mathrm{LF}_{\mathrm{DAP}}$ in $\mathrm{mmHg}^{2}$, respectively) and normalized units (LFnu and LFnu ${ }_{D A P}$ in percentage of total power spectral density, respectively; Task Force, 1996). Additionally, spontaneous baroreceptor reflex sensitivity (BRS) was automatically assessed by using the sequence technique (Steptoe and Vogele, 1990). All functions of the Task Force Monitor have previously been validated and it has been used successfully in recent clinical studies (e.g., Gratze et al., 2005, 2008).

\section{ANALYSIS OF HEMODYNAMIC AND AUTONOMIC VARIABLES}

All hemodynamic and autonomic variables measured by the Task Force Monitor during the last $5 \mathrm{~min}$ of the pre-exercise period (Pre) were computed. After exercise (from the 4 th to the 10th min of recovery), data were averaged on 30-s epochs (i.e., time-varying indices). Data from the last 5-min period of recovery were also averaged to provide a single value for the post-exercise period (Post). Additionally, beat-by-beat HR data collected by the Polar HR monitor was used to calculate the immediate post-exercise HRR and assess parasympathetic reactivation (Buchheit et al., 2007b; i.e., from time 0 to the 10 th min of recovery). HRR was calculated using an iterative technique (Sigmaplot 10; SPSS Science, Chicago, IL, USA) to assess the time constant of the HR decay from a first-order exponential decay curve (HRR $\tau$, s; Buchheit et al., 2007b). To examine the time course of parasympathetic reactivation the square root of the mean of the sum of the squares of differences between adjacent normal R-R intervals (rMSSD) was calculated for each of the 30-s segments of recovery (Goldberger et al., 2006). Data were median filtered in order to smooth out transient outliers in the HRV plots (HRV vs. time in recovery). As recommended the first and last values were not median filtered (Goldberger et al., 2006). Post-exercise HRR $\tau$ and Ln rMSSD have coefficient of variation of $14 \%$ (Buchheit et al., 2008) and 10\% (Buchheit et al., 2010c), respectively in young team-sport players.

\section{CARDIORESPIRATORY MEASURES}

During all running tests, breath-by-breath respiratory gas exchange was measured using an Oxycon Pro metabolic cart. As per the manufacturer's recommendations, the $\mathrm{O}_{2}$ and $\mathrm{CO}_{2}$ analyzers were calibrated using ambient air and a known calibration gas $\left(16 \% \mathrm{O}_{2}\right.$ and $\left.\mathrm{CO}_{2} 5 \%\right)$ prior to each test. Similarly, the ventilometer was calibrated before each test (flow rates of 0.2 and $21 . \mathrm{s}^{-1}$ ). Cardiorespiratory values were averaged over 30 -s periods. Since the validity of the usual criteria for establishing maximal $\mathrm{O}_{2}$ uptake during ramp exercise tests has been questioned (Poole et al., 2008), $\dot{V}_{\mathrm{O}_{2}}$ max was defined as the highest $\dot{V}_{\mathrm{O}_{2}}$ values attained in a 30-s epoch (Millet et al., 2003). A plateau of $\dot{V}_{\mathrm{O}_{2}}$ was observed in about $75 \%$ of the players. $v \dot{V}_{\mathrm{O}_{2}}$ max was defined as the lowest running velocity which elicited $\dot{V}_{\mathrm{O}_{2} \max }$ for at least $1 \mathrm{~min}$ (Billat and Koralsztein, 1996). As described by Whipp et al. (1989), the first ventilatory threshold (VT1) was established as the velocity at which $\dot{V}_{\mathrm{E}_{2}} / \dot{V}_{\mathrm{O}_{2}}$ and $\mathrm{PETO}_{2}$ began to increase without a simultaneous increase in $\mathrm{PETCO}_{2}$. The second ventilatory threshold (VT2) was determined as the velocity corresponding to the first decrease in $\mathrm{PETCO}_{2}$, with a corresponding increase in $\dot{V}_{\mathrm{E}} / \dot{V}_{\mathrm{CO}_{2}}$ after the steady-state phase after the VT1. All threshold measurements were made by visual inspection of graphs of time plotted against each relevant respiratory variable measured in the testing. The visual inspections were made by two experienced exercise physiologists, and the results were compared and then averaged. The maximal HR value observed during the test (5-s average) was defined as players' $H_{\text {max }}$.

\section{ACID-BASE STATUS AND BLOOD LACTATE MEASUREMENT}

A fingertip blood sample was collected $3 \mathrm{~min}$ after the end of each running test and analyzed for blood lactate concentration $\left([\mathrm{La}]_{\mathrm{b}}\right)$ and $\mathrm{pH}$. Blood lactate concentration was measured using a portable automated analyzer (Lactate Pro, Arkray Inc, Kyoto, Japan), which was calibrated with supplied standards prior to each test. Blood pH was analyzed in a blood gas analyzer (Cobas b221, Roche, Mannheim, Germany). The suitability and reproducibility of the Lactate Pro has been previously established throughout the physiological range of 1.0-18.0 $\mathrm{mmoll}^{-1}$ (Pyne et al., 2000).

\section{STATISTICAL ANALYSIS}

Data are presented as means \pm SD or means \pm SE when stated. The distribution of each variable was examined with the KolmogorovSmirnov normality test. Homogeneity of variance was verified with a Levene test. When data were skewed or heteroscedastic (e.g., rMSSD), they were transformed by taking the natural logarithm. The effect of maturity status on anthropometric factors, cardiorespiratory fitness, running performance, baseline (i.e., Pre) hemodynamic and autonomic variables and HRR $\tau$ was assessed with a one-way ANOVA. The effect of maturity status on HRR $\tau$ was further assessed with a one-way ANCOVA, with data adjusted either for $[\mathrm{La}]_{\mathrm{b}}, v \dot{V}_{\mathrm{O}_{2} \max }$ or lean body mass. $\dot{V}_{\mathrm{O}_{2} \max }$ was not used a co-variable because of the limited between-group differences in relative values (Table 1). Changes in hemodynamic and autonomic responses to maximal running exercise were examined using a two-factor ANOVA, with maturity status (pre-, circum-, and post$\mathrm{PHV}$ ), and time (pre- vs. post-exercise) as factors. For all analyses, when a significant interaction was found, Bonferroni's post hoc tests were applied. For each ANCOVA, partial eta-squared $\left(\eta^{2}\right)$ was calculated as measures of effect size. Values of $0.02,0.13$, and above 0.26 were considered as small, medium, and large, respectively (Cohen, 1988). Pearson's product-moment correlation analysis was used to examine the association between pre-exercise autonomic indices and cardiorespiratory fitness and running performance, with all correlations adjusted for age to/from PHV using partial correlations. In addition to statistical significance, the following criteria were adopted to interpret the magnitude of the correlation $(r)$ between test measures: $\leq 0.1$, trivial; $>0.1-$ 0.3 , small; $>0.3-0.5$, moderate; $>0.5-0.7$, large; $>0.7-0.9$, very large; and $>0.9-1.0$, almost perfect. If the $90 \%$ confidence intervals overlapped small positive and negative values the magnitude were deemed unclear; otherwise that magnitude was deemed to be the observed magnitude (Hopkins et al., 2009). Multiple linear regression models (stepwise backward elimination procedure) with HRR $\tau$ as the dependent variable were also used. In the backward procedure, variables with $F$ value $<4$ were removed from the model. All analyses were carried out using Minitab 14.1 (Minitab Inc, Paris, France) or SPSS 19 (SPSS Inc, Chicago, USA) software with the level of significance set at $P \leq 0.05$. 


\section{RESULTS \\ ANTHROPOMETRY, CARDIORESPIRATORY FITNESS, AND RUNNING PERFORMANCE}

The more mature players were as expected older, taller, heavier, and had a greater lean body mass than their less mature counterparts, while total skinfolds were similar for all groups (Table 1). As shown in Table 2, circum-PHV players displayed higher $\dot{V}_{\mathrm{O}_{2} \text { max }}$ than the two other groups, while there were no between-group differences in VT1 or VT2 when expressed as a percentage of $v \dot{V}_{\mathrm{O}_{2} \text { max }}$. $v \dot{V}_{\mathrm{O}_{2} \max }$ and [La] $]_{\mathrm{b}}$ were higher for circum- and post-PHV players compared with pre-PHV, with no significant difference between circum- and post-PHV. Similar between-group differences were found for post-exercise blood $\mathrm{pH}$.

\section{HEMODYNAMIC VARIABLES BEFORE AND AFTER MAXIMAL RUNNING EXERCISE}

Figure 1 illustrates the time course (i.e., 30-s windows) of HR, SV, CO and DAP, SAP and TPR following the incremental running test. Table 3 shows Pre and Post hemodynamic measures for each group. DAP, SAP, MAP, CO, CO were higher after exercise, while
SV was lower. Post-PHV players had higher SAP, SV, and CO than circum- and pre-PHV players, while pre-PHV players had lower $\mathrm{CO}$ than circum- PHV players. There were no other betweengroup differences in hemodynamic variables. There were no changes in TPR after exercise and there were no "maturity $\times$ time" interactions for any of the hemodynamic variables.

\section{AUTONOMIC CONTROL MEASURES BEFORE AND AFTER MAXIMAL RUNNING EXERCISE}

When Pre measures were analyzed independently, there were no between-group differences for any of the autonomic indices (all $P>0.15$ ). Figure 2 illustrates the time course of Ln rMSSD $30 \mathrm{~s}$ and Ln BRS following the maximal running test. Table 4 shows Pre and Post autonomic control measures for each group. Ln $H_{R R}$, Ln rMSSD, and Ln BRS were greater before exercise, while all other measures were greater following exercise. Pre-PHV players had higher Ln $\mathrm{HR}_{\mathrm{RR}}$ than circum- and post-PHV players, while all other variables were similar for the three groups. There was no "maturity status $\times$ time" interactions for any of the autonomic

Table 2 | Cardiopulmonary fitness and running performance of highly trained young soccer players grouped according to maturity status.

\begin{tabular}{|c|c|c|c|c|c|c|c|}
\hline & $\begin{array}{l}v \dot{V}_{\mathrm{O}_{2} \max } \\
\left(\mathrm{km} \mathrm{h}^{-1}\right)\end{array}$ & $\begin{array}{l}\dot{V}_{\mathrm{O}_{2} \max } \\
\left(\mathrm{ml} \min ^{-1} \mathbf{k g}^{-1}\right)\end{array}$ & $\begin{array}{l}\text { VT1 } \\
\left(\% v \dot{V}_{\mathrm{O}_{2} \max }\right)\end{array}$ & $\begin{array}{l}\text { VT2 } \\
\left(\% v \dot{V}_{\mathrm{O}_{2} \max }\right)\end{array}$ & 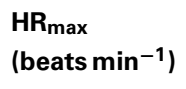 & $\begin{array}{l}\text { Peak }[\mathrm{La}]_{\mathrm{b}} \\
\left(\mathrm{mmoll}^{-1}\right)\end{array}$ & Peak blood pH \\
\hline Pre-PHV & $14.2 \pm 1.3$ & $53.5 \pm 5.8$ & $55 \pm 16$ & $84 \pm 23$ & $199 \pm 10$ & $6.5 \pm 2.9$ & $7.30 \pm 0.04$ \\
\hline Circum-PHV & $15.9 \pm 1.1^{*}$ & $60.6 \pm 5.0^{*}$ & $57 \pm 14$ & $78 \pm 32$ & $196 \pm 7$ & $7.9 \pm 2.0^{*}$ & $7.26 \pm 0.03^{*}$ \\
\hline Post-PHV & $16.6 \pm 0.8^{*}$ & $57.3 \pm 4.2$ & $52 \pm 18$ & $75 \pm 32$ & $192 \pm 10$ & $8.3 \pm 2.0^{*}$ & $7.25 \pm 0.06^{*}$ \\
\hline
\end{tabular}

Values are means $\pm S D$. $\dot{V}_{O_{2} \max }$, maximal oxygen uptake; $v \dot{V}_{O_{2} \max }$ velocity associated with $\dot{V}_{O_{2} \max } ;$ VT1, VT2, velocity at the first and second ventilatory threshold,

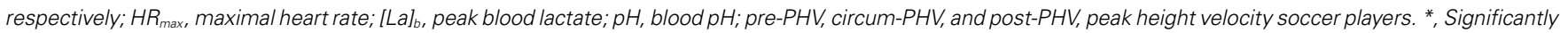
different from pre-PHV $(P<0.05)$.

Table 3 | Resting hemodynamic measures both before and after maximal incremental exercise in highly trained young soccer players grouped according to maturity status.

\begin{tabular}{|c|c|c|c|c|c|c|c|c|c|}
\hline & \multicolumn{2}{|c|}{ Pre-PHV } & \multicolumn{2}{|c|}{ Circum-PHV } & \multicolumn{2}{|c|}{ Post-PHV } & \multirow{2}{*}{$\begin{array}{l}\text { Pubertal status } \\
\text { effect }\end{array}$} & \multirow[t]{2}{*}{ Time } & \multirow[t]{2}{*}{ Interaction } \\
\hline & Pre & Post & Pre & Post & Pre & Post & & & \\
\hline HR (beats $\min ^{-1}$ ) & $75 \pm 9$ & $98 \pm 6$ & $71 \pm 7$ & $99 \pm 8$ & $66 \pm 8$ & $97 \pm 10$ & 0.13 & $\begin{array}{l}<0.001 \\
\text { Pre }<\text { Post }\end{array}$ & 0.28 \\
\hline $\mathrm{DAP}(\mathrm{mmHg})$ & $62 \pm 13$ & $72 \pm 7$ & $63 \pm 8$ & $68 \pm 11$ & $68 \pm 9$ & $71 \pm 11$ & 0.48 & $\begin{array}{l}0.02, \\
\text { Pre }<\text { Post }\end{array}$ & 0.60 \\
\hline $\mathrm{SAP}(\mathrm{mmHg})$ & $100 \pm 11$ & $112 \pm 10$ & $100 \pm 11$ & $114 \pm 14$ & $112 \pm 7$ & $122 \pm 11$ & $\begin{array}{l}\text { 0.001, post > } \\
\text { (circum = pre) }\end{array}$ & $\begin{array}{l}<0.001 \\
\text { Pre }<\text { Post }\end{array}$ & 0.75 \\
\hline MAP (mmHg) & $75 \pm 12$ & $87 \pm 7$ & $77 \pm 9$ & $86 \pm 14$ & $83 \pm 7$ & $93 \pm 12$ & 0.14 & $\begin{array}{l}<0.001 \\
\text { Pre }<\text { Post }\end{array}$ & 0.76 \\
\hline $\mathrm{SV}(\mathrm{ml})$ & $82 \pm 23$ & $67 \pm 18$ & $84 \pm 8$ & $71 \pm 6$ & $94 \pm 15$ & $79 \pm 16$ & $\begin{array}{l}\text { 0.02, post > } \\
\text { (circum = pre) }\end{array}$ & $\begin{array}{l}<0.001 \\
\text { Pre }>\text { Post }\end{array}$ & 0.97 \\
\hline $\mathrm{CO}\left(1 \mathrm{~min}^{-1}\right)$ & $6.0 \pm 1.7$ & $6.5 \pm 1.8$ & $5.9 \pm 0.7$ & $7.0 \pm 0.5$ & $6.1 \pm 1.0$ & $7.6 \pm 1.4$ & 0.22 & $\begin{array}{l}0.001 \\
\text { Pre }<\text { Post }\end{array}$ & 0.38 \\
\hline TPR (dyne s $\mathrm{cm}^{-5}$ ) & $1045 \pm 386$ & $1176 \pm 339$ & $1033 \pm 178$ & $1014 \pm 179$ & $1076 \pm 157$ & $986 \pm 199$ & 0.42 & 0.90 & 0.31 \\
\hline
\end{tabular}

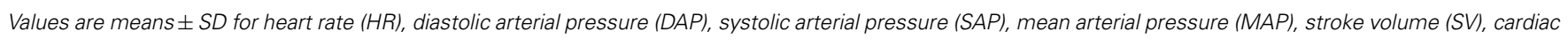

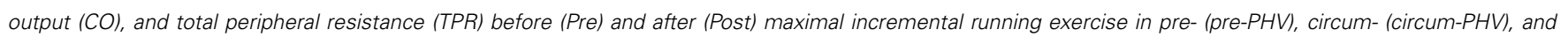
post-(post-PHV) peak height velocity soccer players. 
control measures. Ln rMSSD and Ln BRS were largely correlated both before $(r=0.60)$ and after $(r=0.60)$ exercise.

\section{PREDICTORS OF POST-EXERCISE HRR}

As shown in Table 5, pre-PHV players had faster HRR $\tau$ and greater Post Ln rMSSD than circum- and post-PHV players, while there was no difference between the groups for Ln BRS. However, these between-group differences were non-significant (and $\eta^{2}$ the for "maturity status" effect decreased substantially) when adjusted for either lean body mass, [La $]_{\mathrm{b}}$ or $v \dot{V}_{\mathrm{O}_{2} \max }$. When examining zeroorder correlations between HRR and all proposed independent variables (Table 6), age, maturation, lean body mass, $v \dot{V}_{\mathrm{O}_{2} \text { max }}$ and pre- and post-exercise vagal-related indices were all moderately to largely correlated with HRR; neither TPR, SV nor any index of

Table 4 | Autonomic measures before and after maximal incremental exercise in highly trained young soccer players classified according to maturity status.

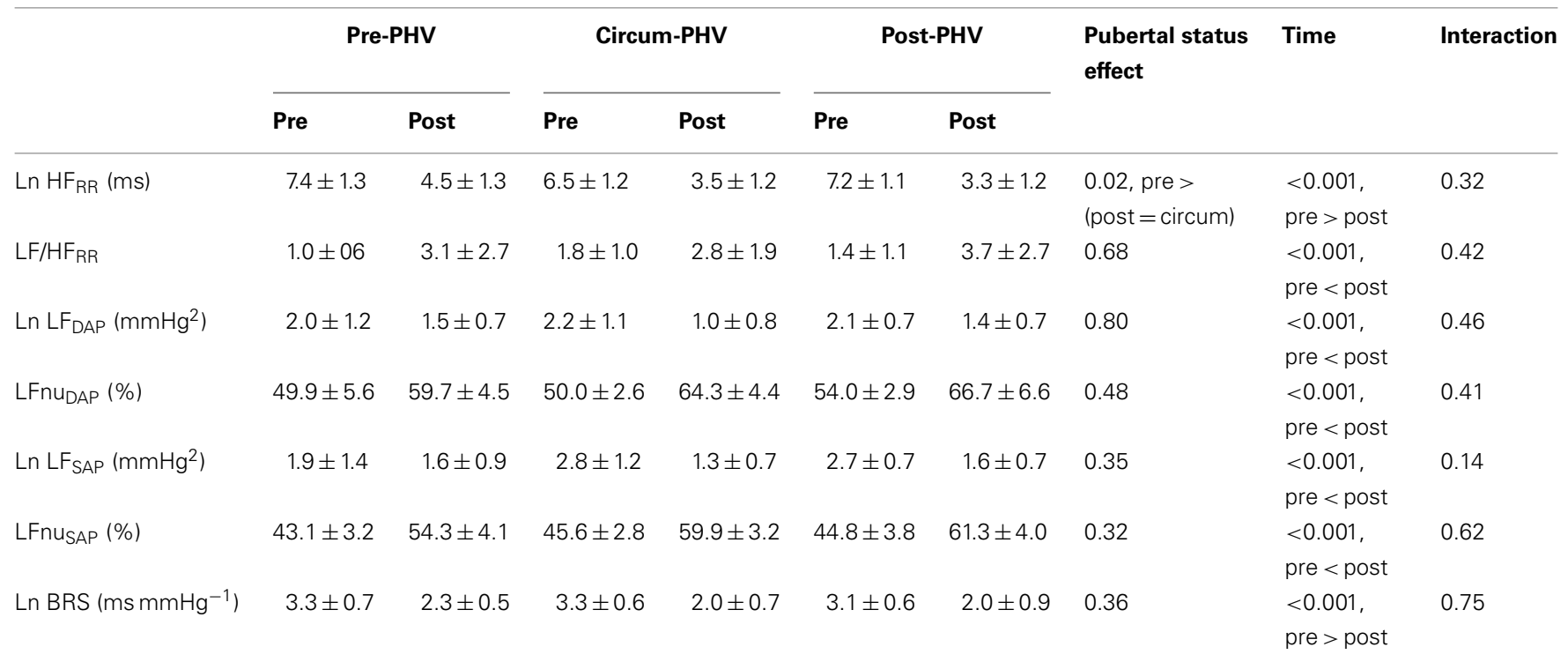

Values are means $\pm S D$ for the logarithm of the high frequency power of $R-R$ intervals $\left(L n H F_{R R}\right)$, low-to-high frequency power of $R-R$ intervals ratio $\left(L F / H F_{R R}\right)$, logarithm of the low frequency power of diastolic arterial pressure ( $L n L F_{D A P}$ ), low frequency power of diastolic arterial pressure expressed in relative unit ( $\left.L F n u_{D A P}\right)$, logarithm of the low frequency power of systolic arterial pressure $\left(L n L F_{S A P}\right)$, low frequency power of systolic arterial pressure expressed in relative unit $\left(L F n u_{S A P}\right)$, and logarithm of baroreflex sensitivity (Ln BRS) before (Pre) and after (Post) the incremental running exercise in pre- (pre-PHV), circum- (circum-PHV), and post-(post-PHV) peak height velocity soccer players.

Table 5 | Indices of post-exercise parasympathetic reactivation in highly trained young soccer players grouped according to maturity status.

\begin{tabular}{|c|c|c|c|c|c|c|}
\hline & & Unadjusted & $\begin{array}{l}\text { Adjusted for } \\
\text { lean body mass }\end{array}$ & $\begin{array}{l}\text { Adjusted } \\
\text { for }[L a]_{b}\end{array}$ & $\begin{array}{l}\text { Adjusted for } \\
\text { Pre Ln rMSSD }\end{array}$ & $\begin{array}{l}\text { Adjusted for } \\
v \dot{V}_{\mathrm{O}_{2} \max }\end{array}$ \\
\hline \multirow[t]{3}{*}{ HRR $\tau(\mathrm{s})$} & pre-PHV & $45 \pm 5$ & $59 \pm 5$ & $54 \pm 5$ & $45 \pm 5$ & $51 \pm 7$ \\
\hline & post-PHV & $73 \pm 5^{*}$ & $60 \pm 7$ & $67 \pm 4$ & $72 \pm 5^{*}$ & $69 \pm 4$ \\
\hline & $\eta^{2}$ & 0.23 & 0.04 & 0.07 & 0.26 & 0.07 \\
\hline \multirow[t]{3}{*}{ Post Ln rMSSD (ms) } & pre-PHV & $2.8 \pm 0.1$ & $2.6 \pm 0.3$ & $2.5 \pm 0.2$ & $2.8 \pm 0.2$ & $2.5 \pm 0.2$ \\
\hline & post-PHV & $2.1 \pm 0.1^{*}$ & $2.2 \pm 0.2$ & $2.2 \pm 0.1$ & $2.1 \pm 0.1^{* \dagger}$ & $2.2 \pm 0.2$ \\
\hline & $\eta^{2}$ & 0.18 & 0.03 & 0.03 & 0.20 & 0.02 \\
\hline \multirow[t]{4}{*}{ Post Ln BRS (ms mmHg ${ }^{-1}$ ) } & pre-PHV & $2.4 \pm 0.2$ & $2.2 \pm 0.3$ & $2.2 \pm 0.2$ & $2.5 \pm 0.2$ & $2.2 \pm 0.3$ \\
\hline & circum-PHV & $2.1 \pm 0.2$ & $2.0 \pm 0.2$ & $2.1 \pm 0.2$ & $2.2 \pm 0.2$ & $2.1 \pm 0.2$ \\
\hline & post-PHV & $2.0 \pm 0.2$ & $2.2 \pm 0.4$ & $2.1 \pm 0.2$ & $1.9 \pm 0.2$ & $2.1 \pm 0.3$ \\
\hline & $\eta^{2}$ & 0.49 & 0.12 & $<0.01$ & 0.09 & $<0.01$ \\
\hline
\end{tabular}

Mean values and least squared means $( \pm S E)$. Time constant of heart rate recovery (HRR $\mathrm{t}$, logarithm of the square root of the mean of the sum of the squares of differences between adjacent normal R-R intervals (Ln rMSSD), and logarithm of baroreflex sensitivity (Ln BRS) in pre- (pre-PHV), circum- (circum-PHV), and post-(post-PHV) peak height velocity soccer players. $\dot{V}_{O_{2} \max }$, maximal oxygen uptake; $v \dot{V}_{O_{2} \max }$, velocity associated with $\dot{V}_{O_{2} \max } ; \eta^{2}$, effect size. ${ }^{*}$, Significant difference vs. Pre-PHV $(P<0.05){ }^{\dagger}$, significant difference vs. Circum-PHV $(P<0.05)$. 
sympathetic activity was associated with HRR. Stepwise multiple regression analyses further showed that the major predictors of HRR $\tau$ were, in order of importance, lean body mass, $[\mathrm{La}]_{\mathrm{b}}$, pre-exercise parasympathetic activity (Ln rMSSD) and $v \dot{V}_{\mathrm{O}_{2} \max }$.

\section{RELATIONSHIPS BETWEEN AUTONOMIC CONTROL MEASURES, CARDIORESPIRATORY FITNESS, AND RUNNING PERFORMANCE}

Some moderate-to-large negative correlations were found between vagal-related indices (i.e., Ln rMSSD and $\mathrm{Ln}_{\mathrm{H}} \mathrm{FF}_{\mathrm{RR}}$ ) measured before exercise and $\dot{V}_{\mathrm{O}_{2} \max }$ and $v \dot{V}_{\mathrm{O}_{2} \max }$ (Table 7). Conversely, sympathetic-related indices (i.e., $\mathrm{LF} / \mathrm{HF}_{\mathrm{RR}}$, LFnu $\mathrm{SAP}_{\mathrm{S}}$, and LFnu $\left.u_{\text {DAP }}\right)$ measured before exercise were positively and largely related to $\dot{V}_{\mathrm{O}_{2} \max }$ and $v \dot{V}_{\mathrm{O}_{2} \max }$. None of these indices were correlated with either VT1 or VT2. When considering Post autonomic correlations coefficients (i.e., $r=-0.44$ to 0.51 ), all values were slightly smaller than those observed for the Pre measures; for simplicity these latter coefficients were therefore not included in Table 7.

\section{DISCUSSION}

In this study, we investigated hemodynamic and autonomic responses to maximal running exercise in highly trained young soccer players with different maturation levels. The main findings were as follows: (1) pre-PHV players displayed faster post-exercise HRR and parasympathetic reactivation compared with the more mature players, $(2)$ there were no "maturity $\times$ time" interactions for any of the hemodynamic or autonomic measures, and (3) multiple regression analyses showed that lean muscle mass, $[\mathrm{La}]_{\mathrm{b}}$, preexercise parasympathetic activity and $v \dot{V}_{\mathrm{O}_{2}}$ max were the strongest predictors of post-exercise HRR.

\section{INFLUENCE OF MATURITY STATUS ON HEMODYNAMIC RECOVERY FOLLOWING MAXIMAL RUNNING EXERCISE}

In the present study, the time constant of HRR was shorter for pre- compared with circum- and post-PHV players. A faster HRR in less mature individuals has previously been reported (e.g., Zafeiridis et al., 2005; Goulopoulou et al., 2006; Buchheit et al., $2010 \mathrm{~b})$, but this is the first time that complementary post-exercise hemodynamic measures have also been concurrently reported as a function of maturation status. While we acknowledge that the estimation of maturity status based on anthropometric measures (Mirwald et al., 2002) might have some limitations, an arbitrary grouping of the players according to chronological age resulted in large disparities in the estimated maturity status of the players within each group. This was likely to abolish between-group differences; the specific impact that aging and/or maturation have on hemodynamic and autonomic control recovery following exercise could therefore not be investigated. When considering both the Pre and Post (i.e., 5-10 min post-exercise) periods (Table 3), we could not find maturational differences in hemodynamic recovery (i.e., no "maturation $\times$ time" interaction), suggesting that except for the HRR period immediately after cessation of exercise ( 0 to 4 th $\mathrm{min}$ ), the relative cardiovascular responses after exercise are not affected by maturation in highly trained young soccer players. Time-varying analysis of these variables (Figure 1) confirm these findings and highlight some interesting maturational differences in the absolute level of various post-exercise hemodynamic measures. For example, despite a similar post-exercise HR, prePHV players presented a lower CO than the other two groups (Figure 1); this latter difference being likely explained by their lower SV. Similarly, the higher CO of post-PHV players compared with circum-PHV was related to their higher SV (since HR was similar). These data show that maturation might selectively affect post-exercise adjustments between the different hemodynamic variables, so that changes in $\mathrm{HR}$ and $\mathrm{CO}$ can be dissociated (Takahashi et al., 2005; i.e., similar HR during recovery does not obligatorily translate into similar CO values in adolescents of differing maturation level). Therefore, while not questioning the maturational differences previously observed in post-exercise

Table 6 | Predictors of the time constant of heart rate recovery using pooled player data.

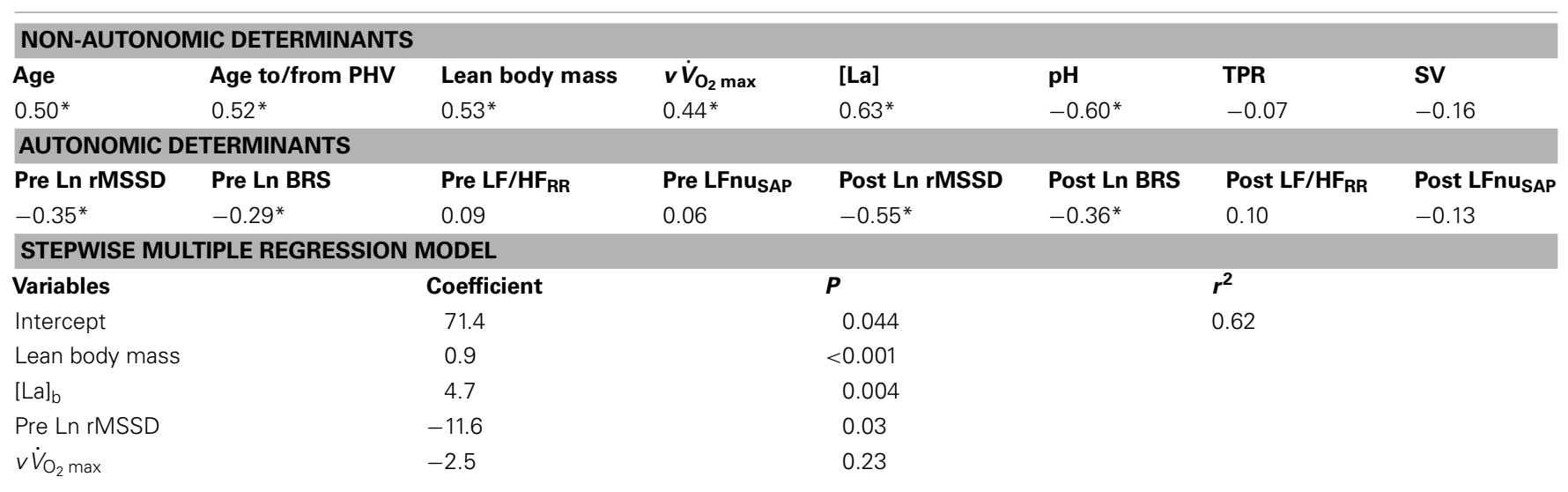

Zero-order correlation coefficients (uppers lines) and coefficient of determination ( $r^{2}$, multiple regression model, lower lines) illustrating the relationships between

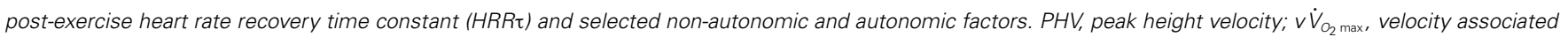

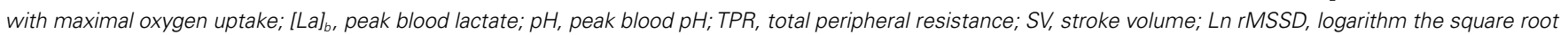
of the mean of the sum of the squares of differences between adjacent normal $R-R$ intervals; $L F / H F_{R R}$, low-to-high frequency power of $R-R$ intervals ratio; $L F$ nu DAP,

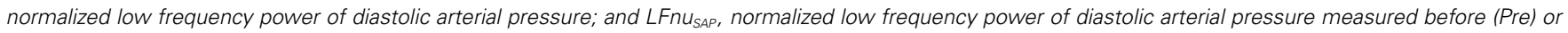
after the maximal incremental running exercise (Post). ${ }^{*}, P<0.05$. 
Table 7 | Correlations between pre-exercise autonomic parameters and cardiorespiratory fitness and running performance in highly trained young soccer players.

\begin{tabular}{|c|c|c|c|c|}
\hline & 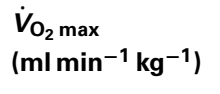 & $\begin{array}{l}v \dot{V}_{\mathrm{O}_{2} \max } \\
\left(\mathrm{km} \mathrm{h}^{-1}\right)\end{array}$ & $\begin{array}{l}\text { VT1 } \\
\left(\% v \dot{V}_{\mathrm{O}_{2} \max }\right)\end{array}$ & $\begin{array}{l}\text { VT2 } \\
\left(\% v \dot{V}_{\mathrm{O}_{2} \max }\right)\end{array}$ \\
\hline Ln rMSSD & $-0.49^{*}$ & -0.39 & -0.29 & -0.03 \\
\hline $\mathrm{Ln} \mathrm{HF}_{\mathrm{RR}}$ & $-0.48^{*}$ & -0.37 & -0.27 & -0.04 \\
\hline$L F / H F_{R R}$ & $0.44^{*}$ & 0.24 & 0.42 & 0.12 \\
\hline Ln LF DAP & 0.11 & -0.23 & 0.04 & 0.08 \\
\hline LFnudAP & $0.55^{*}$ & $0.40^{*}$ & 0.04 & 0.10 \\
\hline Ln LF SAP & 0.02 & -0.42 & 0.04 & 0.18 \\
\hline LFnusAP & $0.40^{*}$ & 0.34 & 0.18 & 0.22 \\
\hline Ln BRS & -0.13 & -0.02 & -0.13 & -0.16 \\
\hline $\mathrm{HRR} \tau$ & 0.08 & 0.18 & 0.05 & 0.10 \\
\hline
\end{tabular}

Logarithm the square root of the mean of the sum of the squares of differences between adjacent normal $R-R$ intervals (Ln rMSSD), logarithm of the high frequency power of $R-R$ intervals ( $\left.L n H F_{R R}\right)$, low-to-high frequency power of $R-R$ intervals ratio $\left(L F / H F_{R R}\right)$, logarithm of the low frequency power of diastolic arterial pressure $\left(L n L F_{D A P}\right)$, low frequency power of diastolic arterial pressure expressed in relative unit ( $\left.L F n U_{D A P}\right)$, logarithm of the low frequency power of systolic arterial pressure ( $\left.L n L F_{S A P}\right)$, low frequency power of systolic arterial pressure expressed in relative unit ( $\left.L F n U_{S A P}\right)$, logarithm of baroreflex sensitivity ( $\left.L n B R S\right)$, time con-

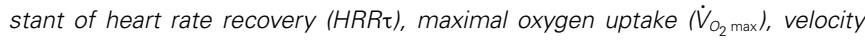
associated with $\dot{V}_{\mathrm{O}_{2} \max }\left(\mathrm{V} \dot{V}_{\mathrm{O}_{2} \max }\right)$ and velocity at the first (VT1) and second (VT2) ventilatory threshold. All correlations are adjusted on age to/from peak height velocity. ${ }^{*}$, Significant with $P<0.05$.

HRR (e.g., Zafeiridis et al., 2005; Goulopoulou et al., 2006; Buchheit et al., 2010b), the present results suggest that inferences to the overall post-exercise hemodynamic responses using HR measures alone may be risky in young athletes.

While training background and cardiorespiratory fitness are strong determinants of cardiac dimension and performance both during and after exercise (Nottin et al., 2002a,b), the similar training histories and the lack of difference in $\dot{V}_{\mathrm{O}_{2} \text { max }}$ between pre- and post-PHV players (Table 1) tend to invalidate this hypothesis. The present post-exercise differences in SV are therefore more likely related to differences in heart size, central blood volume, ventricular filling pressure, and cardiac after-load, which are directly related to systemic blood volume, AP, and vascular peripheral resistance (Rowell, 1986). In the present study, pre-PHV players, who presented with the greatest TPR values also had the lower SV values (Figure 1). The higher TRP observed here in the younger players is also in accordance with the data reported by Nottin et al. (2002a), where non-specifically trained children showed higher systemic vascular resistances than adults. The reason for maturational differences in post-exercise TPR are not well understood, but factors controlling peripheral vasomotor tone may be involved (Nottin et al., 2002a).

\section{INFLUENCE OF MATURITY STATUS ON AUTONOMIC RECOVERY FOLLOWING MAXIMAL RUNNING EXERCISE}

As previously discussed (Malliani et al., 2006), measurement of autonomic activity through $\mathrm{HR}$ and AP variability recordings has its limitations, i.e., even if data are interpreted with appropriate caution, it provides only a qualitative marker of cardiac autonomic regulation. Nevertheless, these measures have the advantage of being non-invasive and able to be assessed in the field, which is well suited for young individuals as in the present study. Research on the impact of maturity status/age on resting autonomic function is limited, and very few studies have examined highly trained athletes. In the present study, we could not find any maturational effect on estimates of resting ANS function, which support the similar resting HRV measures reported in active pre- and post-PHV adolescents by Goulopoulou et al. (2006). In healthy untrained young individuals, Finley et al. (1987) and Finley and Nugent (1995) reported a decreasing trend of overall cardiac autonomic activity from 5 to 24 years. Conversely, Korkushko et al. (1991) and Pikkujamsa et al. (1999) found an increase in overall cardiac autonomic activity during the early years of life with a peak activity at about 20-30 years of age. Differences in training status and methods of data collection/analysis may explain these discrepancies.

As previously reported (Terziotti et al., 2001; Perini and Veicsteinas, 2003), the maximal running exercise employed in the present study resulted in increased $\mathrm{LF} / \mathrm{HF}_{\mathrm{RR}}$ and $\mathrm{LF}$ indices of AP variability, and conversely, in decreased $L n H_{R R}$ and Ln BRS, suggesting decreased parasympathetic modulation and increased sympathetic activity, respectively. Nevertheless, when considering the Pre and Post assessment periods only (Table 4), the magnitude of the changes in autonomic indices were similar for each group (i.e., no "maturation $\times$ time" interaction), suggesting that, as for hemodynamic variables, maturation does not appear to greatly affect autonomic recovery following exercise. The lack of difference in the autonomic control responses measured $5 \mathrm{~min}$ post-exercise between the three groups (Table 4) confirms that maturational differences in autonomic activity, if any, may be limited to the first minutes following exercise cessation, as exemplified by the difference in short-term HRR, which is considered as an index of parasympathetic activity (Buchheit et al., 2007b). The inability to measure ANS activity during exercise and within the first 1-2 min of the post-exercise period (except with the timevarying HRV analysis, see below) with the Task Force Monitor is a significant limitation of the present study. The absence of substantial maturational differences in autonomic responses could be partly related to the fact that the relative intensity of effort was similar for all groups (i.e., maximal, as this was an incremental test to exhaustion) and that all players were highly trained. Additionally, $\mathrm{HR}_{\text {max }}$ did not differ among the groups (Table 2). While higher $\mathrm{HR}_{\max }$ values are generally reported in the younger groups (e.g., Goulopoulou et al., 2006), this lack of difference has previously been reported (Buchheit et al., 2010b) and could be related to the high training status of our young players.

Despite the lack of differences in the changes in autonomic indices after exercise (Table 4), we observed a significantly faster and greater parasympathetic reactivation in the pre-PHV group compared with the other two groups (Figure 2; Table 5). While these results can be seen as contradictory to those discussed above, they confirm that post-exercise time-varying analysis (compared with an ANOVA design) might be a more sensitive way of assessing cardiac post-exercise ANS modulation (especially because of the higher number of measures, which increases statistical 


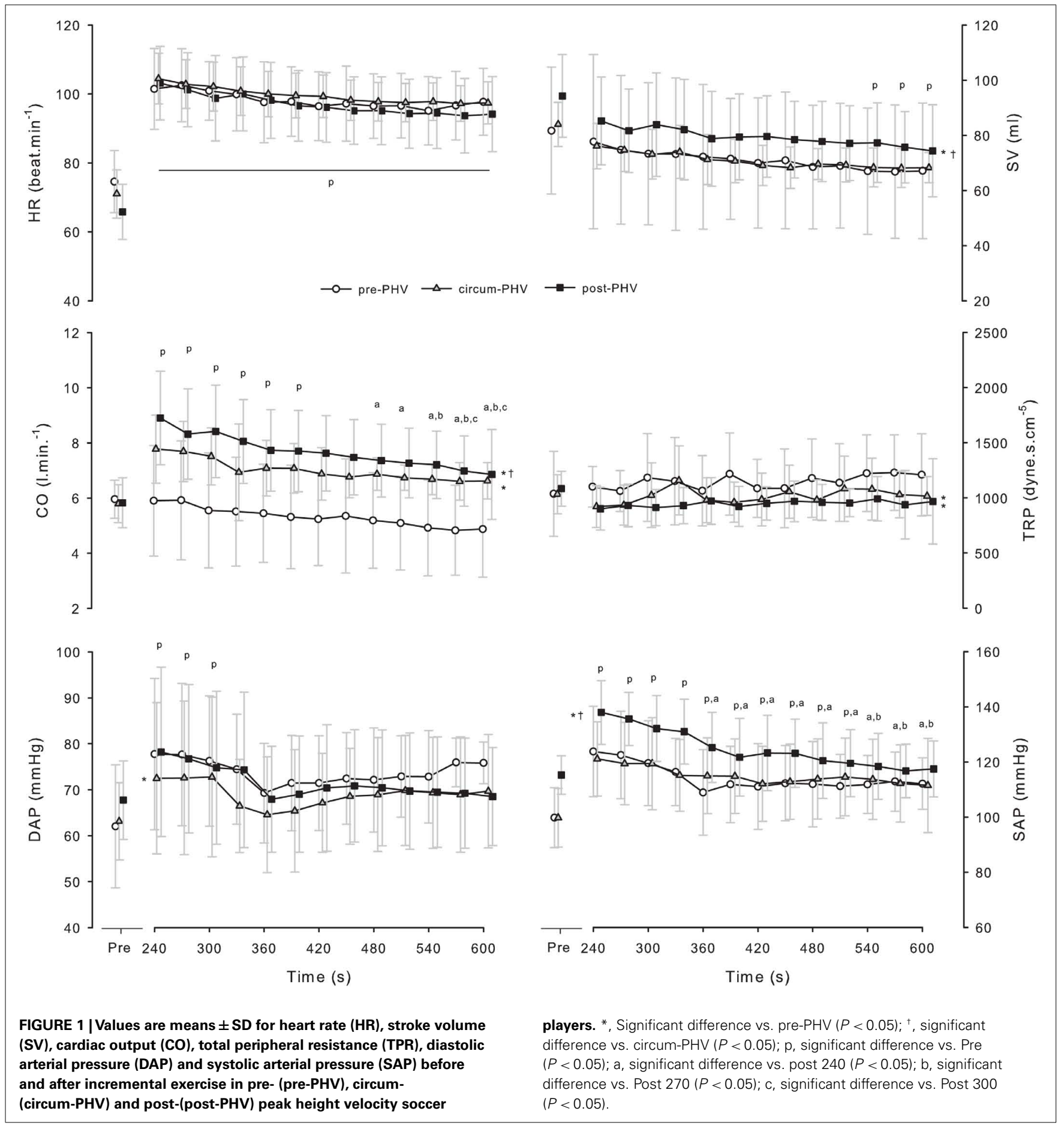

power; Nakamura et al., 2009). Post-exercise ANS regulation has been poorly characterized in adolescents, but greater vagal-related indices have been reported in active (Goulopoulou et al., 2006) and highly trained (Buchheit et al., 2010c) pre-PHV adolescents compared with their older (post-PHV) counterparts. However, the greater parasympathetic reactivation was only apparent when considering Ln rMSSD values, not Ln BRS (Table 5). The lack of between-group differences in BRS is surprising since, like

rMSSD, BRS is thought to be vagally mediated (Parati et al., 1995). However, the mechanism by which BRS function changes with maturation is not clear and may be related to both mechanical (i.e., arterial compliance) and neural (central autonomic function) alterations with age (Lenard et al., 2004). These maturation-related dissociations between these physiological functions can therefore possibly explain the present results and the lower correlation between HRV and BRS measures reported for adolescents in the 


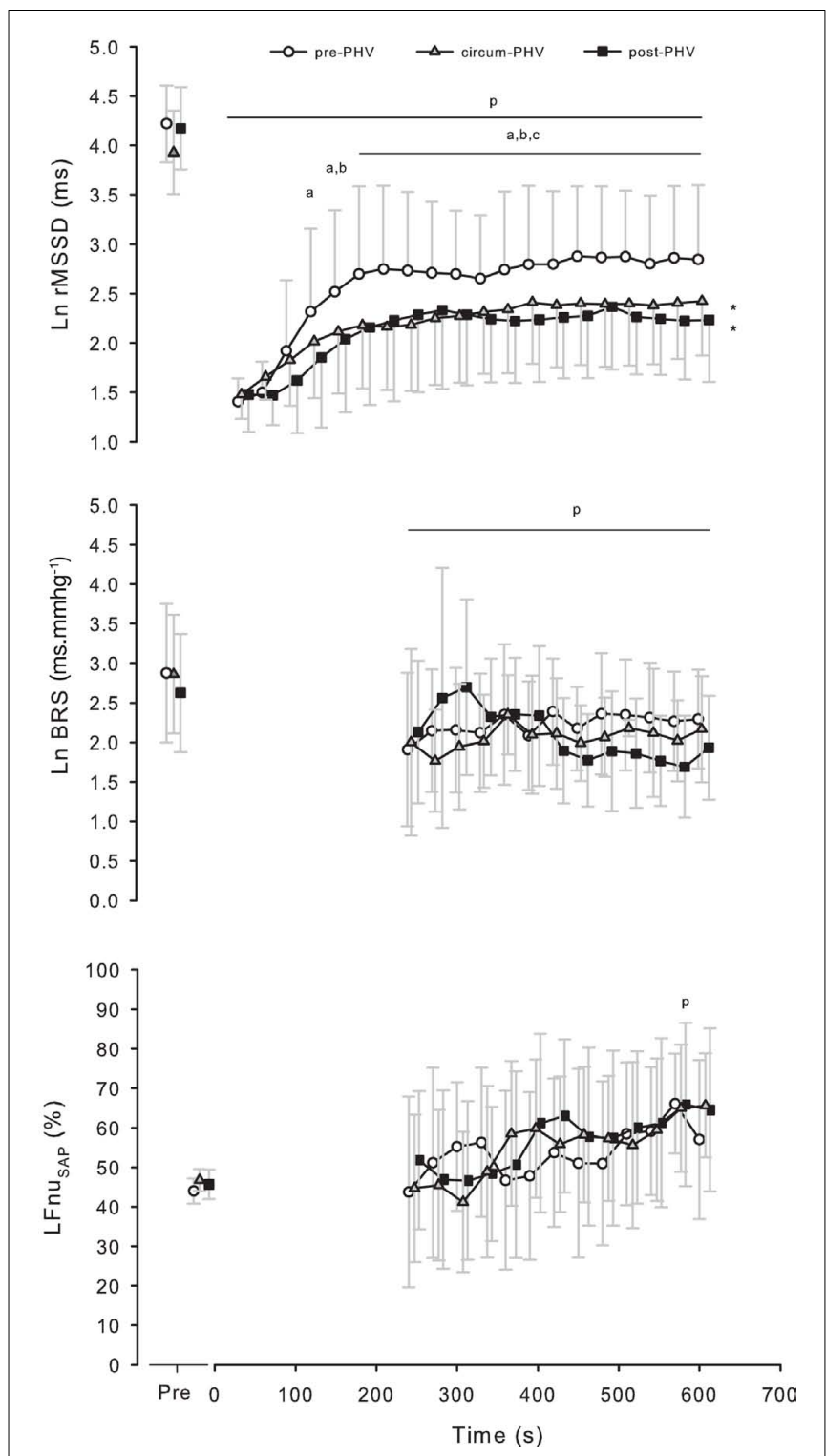

FIGURE 2 | Values are means \pm SD for the natural logarithm of the square root of the mean of the sum of the squares of differences between adjacent normal R-R intervals (Ln rMSSD), baroreceptor reflex sensitivity (Ln BRS) and normalized low frequency power of systolic arterial pressure variability $\left(\mathrm{LFnu}_{\mathrm{SAP}}\right)$ measured on successive 30 s segments before and after incremental exercise in pre- (pre-PHV), circum- (circum-PHV), and post-(post-PHV) peak height velocity soccer players. ${ }^{*}$, Significant difference vs. pre-PHV $(P<0.05)$; $p$, significant difference vs. Pre $(P<0.05)$; a, significant difference vs. Post $30(P<0.05)$; b, significant difference vs. Post $60(P<0.05)$; c, significant difference vs. Post $90(P<0.05)$

present study (Ln BRS vs. Ln rMSSD: $r=0.60$ ) compared with adults ( $r=0.85$; Pellizzer et al., 1996).

\section{PREDICTORS OF HR RECOVERY FOLLOWING MAXIMAL RUNNING EXERCISE}

This is the first time that maturational differences in HRR have been examined simultaneously with hemodynamic, autonomic, and non-autonomic (i.e., body dimension, exercise performance, and humoral variables) variables in highly trained adolescents over a wide range of maturation levels. When examining zeroorder correlations between HRR and all the selected independent variables (Table 6), age, maturation, lean body mass, $v \dot{V}_{\mathrm{O}_{2} \max }$, and pre- and post-exercise vagal-related indices were all moderately to largely correlated with HRR, while neither TPR, SV nor any index of sympathetic activity were associated with HRR. When adjusted for maturational differences in some of the aforementioned variables, between-group differences in HRR $\tau$ were non-significant and the effect sizes $\left(\eta^{2}\right)$ for "maturation" were substantially reduced (Table 5). These results are in line with previous studies in young individuals that have shown significant correlations between HRR and muscle mass (Singh et al., 2008; Buchheit et al., 2010b), post-exercise blood acidosis (Buchheit et al., 2010b), and parasympathetic activity measured at rest (Ohuchi et al., 2000) and following exercise (Goulopoulou et al., 2006). The lack of correlation between HRR and any of the other hemodynamic variables is however a novel finding and confirms that changes in these indices are often dissociated (Takahashi et al., 2005).

While blood $\mathrm{pH}$ and $[\mathrm{La}]_{\mathrm{b}}$ are not the only chemical mediators of the chemoreflex control of HR (Rowell and O'Leary, 1990; Kaufman and Hayes, 2002), neural sympathetic activity may remain accentuated in individuals with higher post-exercise blood acidosis, which likely slows post-exercise parasympathetic reactivation (Buchheit et al., 2007a, 2010b). The lower muscle mass of the less mature children, as well as their slower $v \dot{V}_{\mathrm{O}_{2} \max }$ may also explain their faster HRR, since it is thought that the contribution of the muscle metaboreflex to the cardiorespiratory response is inversely related to muscle mass and (isometric) contraction intensity (Iellamo et al., 1999). Irrespective of the blood acid-base status, the central command for sympathetic drive is also thought to be related to muscle mass recruitment (Franke et al., 2000).

Since HRR and post-exercise vagal-related HRV indices were reported to be positively correlated (Javorka et al., 2003; Goulopoulou et al., 2006), post-exercise cardiac parasympathetic modulation has been suggested to be a strong determinant of HRR. Nevertheless, correlation does not imply cause-effects. It is worth noting that, as HRR, post-exercise vagal-related HRV indices (Buchheit et al., 2007a) and BRS (Terziotti et al., 2001) are significantly affected by exercise intensity and the associated residual sympathetic overactivity. Along these lines, in the present study, between-group differences in parasympathetic reactivation (i.e., time-varying rMSSD; Figure 2) paralleled those observed in HRR. Additionally, when adjusted for differences in $[\mathrm{La}]_{\mathrm{b}}$, lean body mass or $v \dot{V}_{\mathrm{O}_{2} \text { max }}$, between-group differences in Post Ln rMSSD and Ln BRS to a less extent, were not significant anymore and the effect sizes for "maturation" were substantially reduced (Table 5). This clearly demonstrates that both HRR and postexercise indices of cardiac parasympathetic modulation respond similarly to homeostasis perturbations. This in turn questions the use of a measure (i.e., HRV) to explain the physiological determinant of the others (i.e., HRR; Javorka et al., 2003; Goulopoulou et al., 2006). This view is confirmed by the fact that when all suggested predictors of HRR were examined together, the stepwise multiple regression analysis excluded post-exercise measures 
of parasympathetic modulation from the model (Table 6). The major predictors of HRR $\tau$ were in fact reduced to, in order of importance, lean body mass, $[\mathrm{La}]_{\mathrm{b}}$, pre-exercise parasympathetic activity (Ln rMSSD) and $v \dot{V}_{\mathrm{O}_{2}} \max$.

A novel finding of the present study is that there were no significant correlations between HRR $\tau$ and any of the indices of sympathetic activity (i.e., $\mathrm{LF}_{\mathrm{H}} \mathrm{HF}_{\mathrm{RR}}$ and $\mathrm{LF}$ indices of $\mathrm{AP}$ variability). Along the same lines, compared with the more mature groups, post-exercise sympathetic activity was not significantly lower in the pre-PHV players (Figure 2) who displayed a faster HRR and lower post-exercise HR (Figure 1). Conversely, a higher sympathetic activity was expected in the post-PHV players who displayed higher SAP (Figure 1) and probably a greater central command for sympathetic drive, which is thought to be related to both muscle mass recruitment (Franke et al., 2000) and exercise intensity. These results are surprising since sympathetic activity is thought to play an important role in regulating post-exercise hemodynamics in adults (Savin et al., 1982). In our present data the possible lack of sensitivity of the present AP measures (vascular unloading technique) and the lower reliability of relative indices (i.e., ratio) compared with absolute values (Al Haddad et al., 2011) could have masked potential maturational differences in sympathetic activity (i.e., Type 2 error), and therefore further research in adolescents is still warranted. Furthermore the high training histories of the young soccer players in the present study, as well as possible maturational differences in the sympathetic systems effect on HR (Lenard et al., 2004) could also explain some of the present results. In conclusion, the present data suggest that HRR is likely related, in addition to important metaboreflex-related mechanisms, to differences in intrinsic parasympathetic function (i.e., resting) rather than to post-exercise ANS function.

\section{ASSOCIATIONS BETWEEN AUTONOMIC INDICES, CARDIORESPIRATORY FITNESS, AND RUNNING PERFORMANCE}

Recently, the assessment of pre- and post-exercise ANS activity in individual athletes and team-sport players has been of great interest to researchers (Iellamo et al., 2002; Iwasaki et al., 2003; Garet et al., 2004; Gratze et al., 2005, 2008; Bosquet et al., 2007; Buchheit et al., 2008, 2010a; Manzi et al., 2009). While Pagani and Lucini (2009) presented the ANS as an "interface" between actual physical fitness and final running performance, whether a greater pre-exercise sympathetic or parasympathetic activity is associated with enhanced running performance is still debatable (Iellamo et al., 2002; Buchheit and Gindre, 2006; Bosquet et al., 2007; Gratze et al., 2008). It is also worth noting that none of our players were underperforming or complaining about any type of fatigue at the time of the assessments. This is of great importance since a state of non-functional overreaching or overtraining might modify the possible relationship between ANS function and

\section{REFERENCES}

Al Haddad, H., Laursen, P. B., Chollet, D., Ahmaidi, S., and Buchheit, M. (2011). Reliability of resting and postexercise heart rate measures. Int. J. Sports Med. 32, 598-605.

Beunen, G. P. (1989). "Biologic age in pediatric exercise research," in

performance (Bosquet et al., 2008). In the present study in highly trained young soccer players, $\dot{V}_{\mathrm{O}_{2} \text { max }}$ and $v \dot{V}_{\mathrm{O}_{2} \text { max }}$ were negatively correlated with vagal-related indices and positively associated with sympathetic-related indices (Table 7). These results contrast with previous data in physically active adolescents, where a positive relationship between cardiac parasympathetic activity and estimated $\dot{V}_{\mathrm{O}_{2}}$ max was reported (Buchheit et al., 2007c). Increased vagal-related indices (Buchheit and Gindre, 2006), as well as a low basal sympathetic tone (Gratze et al., 2005, 2008) have also been reported to correlate positively with cardiorespiratory fitness and running performance in moderately trained adult athletes. Additionally, in adult runners, parallel changes have been observed between endurance performance and parasympathetic function (Buchheit et al., 2010a). Nevertheless, in athletes undertaking heavy training loads (i.e., Olympic rowing champions; Iellamo et al., 2002) and/or prolonged training (training for a year for long-distance events; Iwasaki et al., 2003; Manzi et al., 2009), a conversion from a ANS parasympathetic toward a sympathetic predominance was associated with improved physical performance. Similarly in well-trained adult runners, Bosquet et al. (2007) reported a negative correlation between vagal-related indices and $\dot{V}_{\mathrm{O}_{2} \text { max }}$. Taken together, these findings suggest that the relationship between cardiorespiratory fitness, running performance and autonomic function might be training-status dependent, with a shift from a beneficial parasympathetic to a sympathetic predominance with increasing training load (Iellamo et al., 2002; Iwasaki et al., 2003; Manzi et al., 2009). Further longitudinal data on highly trained young soccer players are nevertheless needed to describe the time course of ANS function throughout a season (Buchheit et al., 2010c, 2011) and its possible link with physical performance.

To conclude, the present findings show that hemodynamic and autonomic control responses to exercise are only weakly affected by maturation in highly trained soccer players. The present results show that post-exercise HR responses do not consistently match those of $\mathrm{CO}$ and other hemodynamic variables, which questions the use of HR measures alone to assess overall hemodynamic responses following maximal (running) exercise in young individuals differing in maturation status. While the correlations shown in the present study do not establish a cause-and-effect relationship between the observed variables, the present data suggest that HRR is likely related to lean mass muscle, blood acidosis, running performance (i.e., $v \dot{V}_{\mathrm{O}_{2} \text { max }}$ in the present case), and intrinsic parasympathetic function, with no evident impact of post-exercise ANS function. Additional longitudinal studies investigating the changes in autonomic function throughout the season and their relationship with physical performance are also still warranted.

\section{ACKNOWLEDGEMENT}

The authors thank the players for their enthusiastic participation.

Bosquet, L., Gamelin, F. X., and Berthoin, S. (2007). Is aerobic endurance a determinant of cardiac autonomic regulation? Eur. J. Appl. Physiol. 100, 363-369.

Bosquet, L., Merkari, S., Arvisais, D., and Aubert, A. E. (2008). Is heart rate a convenient tool to monitor over-reaching? A systematic review of the literature. Br. J. Sports Med. 42, 709-714.

Buchheit, M., Chivot, A., Parouty, J., Mercier, D., Al Haddad, H., Laursen, P. B., and Ahmaidi, S. (2010a). Monitoring endurance running performance using cardiac 
parasympathetic function. Eur. J. Appl. Physiol. 108, 1153-1167.

Buchheit, M., Duche, P., Laursen, P. B., and Ratel, S. (2010b). Postexercise heart rate recovery in children: relationship with power output, blood pH, and lactate. Appl. Physiol. Nutr. Metab. 35, 142-150.

Buchheit, M., Mendez-Villanueva, A., Quod, M., and Bourdon, P. (2010c). Determinants of the variability of heart rate measures during a competitive period in young soccer players. Eur. J. Appl. Physiol. 109, 869-878.

Buchheit, M., Mendez-Villanueva, A., Simpson, B. M., and Bourdon, P. C. (2010d). Match running performance and fitness in youth soccer. Int. J. Sports Med. 31, 818-825.

Buchheit, M., Mendez-Villanueva, A., Simpson, B. M., and Bourdon, P. C. (2010e). Repeated-sprint sequences during youth soccer matches. Int. J. Sports Med. 31, 709-716.

Buchheit, M., and Gindre, C. (2006). Cardiac parasympathetic regulation: respective associations with cardiorespiratory fitness and training load. Am. J. Physiol. Heart Circ. Physiol. 291, H451-H458.

Buchheit, M., Laursen, P. B., and Ahmaidi, S. (2007a). Parasympathetic reactivation after repeated sprint exercise. Am. J. Physiol. Heart Circ. Physiol. 293, H133-H141.

Buchheit, M., Papelier, Y., Laursen, P. B., and Ahmaidi, S. (2007b). Noninvasive assessment of cardiac parasympathetic function: postexercise heart rate recovery or heart rate variability? Am. J. Physiol. Heart Circ. Physiol. 293, H8-H10.

Buchheit, M., Platat, C., Oujaa, M., and Simon, C. (2007c). Habitual physical activity, physical fitness and heart rate variability in preadolescents. Int. J. Sports Med. 28, 204-210.

Buchheit, M., Millet, G. P., Parisy, A., Pourchez, S., Laursen, P. B., and Ahmaidi, S. (2008). Supramaximal training and post-exercise parasympathetic reactivation in adolescents. Med. Sci. Sports Exerc. 40, 362-371.

Buchheit, M., Simpson, M. B., Al Haddad, H., Bourdon, P. C., and MendezVillanueva, A. (2011). Monitoring changes in physical performance with heart rate measures in young soccer players. Eur. J. Appl. Physiol. PMID: 21656232. [Epub ahead of print].

Cohen, J. (1988). Statistical Power Analysis for the Behavioral Sciences. Hillsdale: Lawrence Erlbaum.

Finley, J. P., and Nugent, S. T. (1995). Heart rate variability in infants, children and young adults. J. Auton. Nerv. Syst. 51, 103-108.
Finley, J. P., Nugent, S. T., and Hellenbrand, W. (1987). Heart-rate variability in children. Spectral analysis of developmental changes between 5 and 24 years. Can. J. Physiol. Pharmacol. 65, 2048-2052.

Fortin, J., Habenbacher, W., Heller, A., Hacker, A., Grullenberger, R., Innerhofer, J., Passath, H., Wagner, C., Haitchi, G., Flotzinger, D., Pacher, R., and Wach, P. (2006). Non-invasive beat-to-beat cardiac output monitoring by an improved method of transthoracic bioimpedance measurement. Comput. Biol. Med. 36, 1185-1203.

Franke, W. D., Boettger, C. F., and Mclean, S. P. (2000). Effects of varying central command and muscle mass on the cardiovascular responses to isometric exercise. Clin. Physiol. 20, 380-387.

Garet, M., Tournaire, N., Roche, F., Laurent, R., Lacour, J. R., Barthelemy, J. C., and Pichot, V. (2004). Individual Interdependence between nocturnal ANS activity and performance in swimmers. Med. Sci. Sports Exerc. 36, 2112-2118.

Gilsanz, V., and Ratib, O. (2005). Hand Bone Age. Heidelberg: SpringerVerlag.

Goldberger, J., Le, F. K., Lahiri, M., Kannankeril, P., Ng, J., and Kadish, A. (2006). Assessment of parasympathetic reactivation after exercise. Am. J. Physiol. Heart Circ. Physiol. 290, H2446-H2452.

Goulopoulou, S., Heffernan, K. S., Fernhall, B., Yates, G., Baxter-Jones, A. D., and Unnithan, V. B. (2006). Heart rate variability during recovery from a wingate test in adolescent males. Med. Sci. Sports Exerc. 38, 875-881.

Gratze, G., Mayer, H., Luft, F. C., and Skrabal, F. (2008). Determinants of fast marathon performance: low basal sympathetic drive, enhanced postcompetition vasodilatation and preserved cardiac performance after competition. Br. J. Sports Med. 42, 582-588.

Gratze, G., Rudnicki, R., Urban, W., Mayer, H., Schlogl, A., and Skrabal, F. (2005). Hemodynamic and autonomic changes induced by Ironman: prediction of competition time by blood pressure variability. J. Appl. Physiol. 99, 1728-1735.

Hopkins, W. G., Marshall, S. W., Batterham, A. M., and Hanin, J. (2009). Progressive statistics for studies in sports medicine and exercise science. Med. Sci. Sports Exerc. 41, 3-13.

Iellamo, F., Legramante, J. M., Pigozzi, F., Spataro, A., Norbiato, G., Lucini, D., and Pagani, M. (2002). Conversion from vagal to sympathetic predominance with strenuous training in high-performance world class athletes. Circulation 105, 2719-2724.

Iellamo, F., Massaro, M., Raimondi, G. Peruzzi, G., and Legramante, J. M. (1999). Role of muscular factors in cardiorespiratory responses to static exercise: contribution of reflex mechanisms. J. Appl. Physiol. 86, 174-180.

Imai, K., Sato, H., Hori, M., Kusuoka, H. Ozaki, H., Yokoyama, H., Takeda, H., Inoue, M., and Kamada, T. (1994). Vagally mediated heart rate recovery after exercise is accelerated in athletes but blunted in patients with chronic heart failure. J. Am. Coll. Cardiol. 24, 1529-1535.

Iwasaki, K., Zhang, R., Zuckerman, J. H., and Levine, B. D. (2003). Doseresponse relationship of the cardiovascular adaptation to endurance training in healthy adults: how much training for what benefit? J. Appl. Physiol. 95, 1575-1583.

Javorka, M., Zila, I., Balharek, T., and Javorka, K. (2003). On- and offresponses of heart rate to exercise relations to heart rate variability. Clin. Physiol. Funct. Imaging 23, 1-8.

Kaufman, M. P., and Hayes, S. G. (2002). The exercise pressor reflex. Clin. Auton. Res. 12, 429-439.

Korkushko, O. V., Shatilo, V. B. Plachinda Yu, I., and Shatilo, T. V. (1991). Autonomic control of cardiac chronotropic function in man as a function of age: assessment by power spectral analysis of heart rate variability. J. Auton. Nerv. Syst. 32, 191-198.

Lenard, Z., Studinger, P., Mersich, B., Kocsis, L., and Kollai, M. (2004) Maturation of cardiovagal autonomic function from childhood to young adult age. Circulation 110, 2307-2312.

Malina, R. M., Bouchard, C., and Baror, O. (2004). Growth, Maturation and Physical Activity. Champaing, IL: Human Kinetics.

Malliani, A., Julien, C., Billman, G. E., Cerutti, S., Piepoli, M. F., Bernardi, L., Sleight, P., Cohen, M. A., Tan, C. O., Laude, D., Elstad, M., Toska, K., Evans, J. M., and Eckberg, D. L. (2006). Cardiovascular variability is/is not an index of autonomic control of circulation. J. Appl. Physiol. 101, 684-688.

Manzi, V., Castagna, C., Padua, E., Lombardo, M., D'ottavio, S., Massaro, M., Volterrani, M., and Iellamo, F. (2009). Dose-response relationship of autonomic nervous system responses to individualized training impulse in marathon runners. Am. J. Physiol. Heart Circ. Physiol. 296, H1733-H1740.
Marfell-Jones, M. J., Olds, T., Stewart, A. D., and Carter, L. (2006). International Standards for Anthropometric Assessment. International Society for the Advancement of Kinanthropometry (ISAK), Potchefstroom, South Africa.

Mendez-Villanueva, A., Buchheit, M., Kuitunen, S., Douglas, A., Peltola, E., and Bourdon, P. (2011). Age-related differences in acceleration, maximum running speed, and repeatedsprint performance in young soccer players. J. Sports Sci. 29, 477-484.

Millet, G. P., Libicz, S., Borrani, F., Fattori, P., Bignet, F., and Candau, R. (2003). Effects of increased intensity of intermittent training in runners with differing VO2 kinetics. Eur. J. Appl. Physiol. 90, 50-57.

Mirwald, R. L., Baxter-Jones, A. D., Bailey, D. A., and Beunen, G. P. (2002). An assessment of maturity from anthropometric measurements. Med. Sci. Sports Exerc. 34, 689-694.

Nakamura, F. Y., Soares-Caldeira, L. F., Laursen, P. B., Polito, M. D., Leme, L. C., and Buchheit, M. (2009). Cardiac autonomic responses to repeated shuttle sprints. Int. J. Sports Med. 30, 808-813.

Nottin, S., Vinet, A., Mandigout, S., Nguyen, L. D., Stecken, F., Ounissi, F., Lecoq, A. M., and Obert, P. (2002a). Left ventricular dynamics during early recovery from maximal exercise in boys and men. Med. Sci. Sports Exerc. 34, 1951-1957.

Nottin, S., Vinet, A., Stecken, F., N'guyen, L. D., Ounissi, F., Lecoq, A. M., and Obert, P. (2002b). Central and peripheral cardiovascular adaptations to exercise in endurancetrained children. Acta Physiol. Scand. 175, 85-92.

Ohuchi, H., Suzuki, H., Yasuda, K., Arakaki, Y., Echigo, S., and Kamiya, T. (2000). Heart rate recovery after exercise and cardiac autonomic nervous activity in children. Pediatr Res. 47, 329-335.

Pagani, M., and Lucini, D. (2009). Can autonomic monitoring predict results in distance runners? Am. J. Physiol. Heart Circ. Physiol. 296, H1721-H1722.

Parati, G., Ongaro, G., Bilo, G., Glavina, F., Castiglioni, P., Di Rienzo, M., and Mancia, G. (2003). Non-invasive beat-to-beat blood pressure monitoring: new developments. Blood Press. Monit. 8, 31-36.

Parati, G., Saul, J. P., Di Rienzo, M., and Mancia, G. (1995). Spectral analysis of blood pressure and heart rate variability in evaluating cardiovascular regulation. A critical appraisal. Hypertension 25, 1276-1286. 
Pellizzer, A. M., Kamen, P. W., Jackman, G., Brazzale, D., and Krum, H. (1996). Non-invasive assessment of baroreflex sensitivity and relation to measures of heart rate variability in man. Clin. Exp. Pharmacol. Physiol. 23, 621-624.

Perini, R., and Veicsteinas, A. (2003). Heart rate variability and autonomic activity at rest and during exercise in various physiological conditions. Eur. J. Appl. Physiol. 90, 317-325.

Pikkujamsa, S. M., Makikallio, T. H., Sourander, L. B., Raiha, I. J., Puukka, P., Skytta, J., Peng, C. K., Goldberger, A. L., and Huikuri, H. V. (1999). Cardiac interbeat interval dynamics from childhood to senescence: comparison of conventional and new measures based on fractals and chaos theory. Circulation 100, 393-399.

Poole, D. C., Wilkerson, D. P., and Jones, A. M. (2008). Validity of criteria for establishing maximal $\mathrm{O} 2$ uptake during ramp exercise tests. Eur. J. Appl. Physiol. 102, 403-410.

Pyne, D. B., Boston, T., Martin, D. T., and Logan, A. (2000). Evaluation of the lactate pro blood lactate analyser. Eur. J. Appl. Physiol. 82, 112-116.

Ratel, S., Duche, P., and Williams, C. A. (2006). Muscle fatigue during highintensity exercise in children. Sports Med. 36, 1031-1065.
Rodriguez, G., Moreno, L. A., Blay, M. G., Blay, V. A., Fleta, J., Sarria, A., and Bueno, M. (2005). Body fat measurement in adolescents: comparison of skinfold thickness equations with dual-energy X-ray absorptiometry. Eur. J. Clin. Nutr. 59, 1158-1166.

Rowell, L. B. (1986). Human Circulation: Regulation During Physical Stress. New York: Oxford University Press.

Rowell, L. B., and O’Leary, D. S. (1990). Reflex control of the circulation during exercise: chemoreflexes and mechanoreflexes. J. Appl. Physiol. 69, 407-418.

Savin, W. M., Davidson, D. M., and Haskell, W. L. (1982). Autonomic contribution to heart rate recovery from exercise in humans. J. Appl. Physiol. 53, 1572-1575.

Singh, T. P., Rhodes, J., and Gauvreau, K. (2008). Determinants of heart rate recovery following exercise in children. Med. Sci. Sports Exerc. 40, 601-605.

Slaughter, M. H., Lohman, T. G., Boileau, R. A., Horswill, C. A., Stillman, R. J., Van Loan, M. D., and Bemben, D. A. (1988). Skinfold equations for estimation of body fatness in children and youth. Hum. Biol. 60, 709-723.

Steptoe, A., and Vogele, C. (1990). Cardiac baroreflex function during postural change assessed using non-invasive spontaneous sequence analysis in young men. Cardiovasc. Res. 24, 627-632.

Takahashi, T., Hayano, J., Okada, A. Saitoh, T., and Kamiya, A. (2005). Effects of the muscle pump and body posture on cardiovascular responses during recovery from cycle exercise. Eur. J. Appl. Physiol. 94, 576-583.

Task Force. (1996). Heart rate variability: standards of measurement, physiological interpretation and clinical use. Task Force of the European Society of Cardiology and the North American Society of Pacing and Electrophysiology. Circulation 93, 1043-1065.

Terziotti, P., Schena, F., Gulli, G. and Cevese, A. (2001). Post-exercise recovery of autonomic cardiovascular control: a study by spectrum and cross-spectrum analysis in humans. Eur. J. Appl. Physiol. 84, 187-194.

Vissing, J. (2000). Muscle reflex and central motor control of neuroendocrine activity, glucose homeostasis and circulation during exercise. Acta Physiol. Scand. Suppl. 647, 1-26.

Whipp, B. J., Davis, J. A., and Wasserman, K. (1989). Ventilatory control of the 'isocapnic buffering' region in rapidly-incremental exercise. Respir. Physiol. 76, 357-367.

Zafeiridis, A., Dalamitros, A., Dipla, K., Manou, V., Galanis, N., and
Kellis, S. (2005). Recovery during high-intensity intermittent anaerobic exercise in boys, teens, and men. Med. Sci. Sports Exerc. 37, 505-512.

Conflict of Interest Statement: The authors declare that the research was conducted in the absence of any commercial or financial relationships that could be construed as a potential conflict of interest.

Received: 07 June 2011; accepted: 19 September 2011; published online: 10 October 2011.

Citation: Buchheit M, A1 Haddad H, Mendez-Villanueva A, Quod MJ and Bourdon PC (2011) Effect of maturation on hemodynamic and autonomic control recovery following maximal running exercise in highly trained young soccer players. Front. Physio. 2:69. doi: 10.3389/fphys.2011.00069

This article was submitted to Frontiers in Exercise Physiology, a specialty of Frontiers in Physiology.

Copyright (C) 2011 Buchheit, A1 Haddad, Mendez-Villanueva, Quod and Bourdon. This is an open-access article subject to a non-exclusive license between the authors and Frontiers Media SA, which permits use, distribution and reproduction in other forums, provided the original authors and source are credited and other Frontiers conditions are complied with. 